The underlying aetiology of PCI, ie, mesenteric ischaemia or bowel infarction, is then the presenting disease. The natural course of PCI, except when it is secondary to bowel ischaemia, is usually benign. It has been suggested that gross pneumatosis and pneumatosis lasting longer than a few days also implies a benign course. Many cysts disappear spontaneously and may never come to notice.

The diagnosis of PCI is usually made on a plain X-ray of the abdomen, on which it appears as translucent clusters along the margins of the bowel wall. On endoscopy the sub-mucosal cystic lesions project into lumen like multiple polyps, which tend to bleed on contact. Barium enema shows multiple rounded filling defects and the picture can be mistaken for polyposis, carcinoma or ulcerative colitis. Ultrasound shows a thickened bowel wall with multiple cystic lesions and is more sensitive than a plain radiograph. Computed tomography is most sensitive but not used for routine clinical evaluation.

1 Knechtle SJ, Davidoff AM, Rice RP. Pneumatosis intestinalis, surgical management and clinical outcome. Ann Surg 1990; 12: 160-5.

2 Rogy MA, Mirza DF, Kovats E, Rauhs R. Pneumatosis cystoides intestinalis. Int $\mathcal{f}$ Colorectal Dis 1990; 5: 120-4.

3 Luks FI, Chung MA, Brandt ML, Hertecant J, Roy CC Blanchard H. Pneumatosis and pneumoperitoneum in chronic idiopathic intestinal pseudo-obstruction. $\mathcal{F}$ Pediat Surg 1991; 26: 1384-6.

4 Kelly B, Cooper GG, Mills J. Pneumoperitoneum due to $\mathrm{PCI}$ in a patient with strangulated femoral hernia. $\mathrm{Br} \mathcal{f} \mathrm{Clin}$ Pract 1993; 47: 272 .

5 Yale CE, Balish E. The natural course of Clostridium perfringens-induced pneumatosis cystoides intestinalis. $\mathscr{F}$ Med 1992; 23: 279-88.
The treatment of pneumatosis secondary to ischaemia requires prompt resection of the affected bowel. Box 2 enumerates factors which suggest bowel ischaemia or gangrene in a case of pneumatosis. These patients have a poor prognosis and should undergo urgent laparotomy. In its 'benign' non-ischaemic form, PCI rarely requires treatment unless symptomatic in which case metronidazole, amoxycillin or hyperbaric oxygen can be used. However, as the 'benign' form is often self-limiting it is doubtful whether any treatment is required at all.

\section{Final diagnosis}

Pneumatosis cystoides intestinalis

Keywords: pneumatosis cystoides intestinalis, sigmoid volvulus

\section{Acute Elderly Services, Orsett Hospital, Orsett, Grays, Essex RM16 3EU, UK GH Jenner}

Accepted 1 June 1995
6 Van Leeuwen JC, Nossent JC. Pneumatosis intestinalis in mixed connective tissue disease. Neth $\mathcal{F}$ Med 1992; 40 299-302.

7 Jensen R, Gutnik SH. Pneumatosis cystoides intestinalis, a complication of colonscopic polypectomy. $S D \mathcal{F M e d} 1991$ 44: 177-9.

8 Cho KC, Simmons MZ, Baker SR, Cappell MS. Spontaneous dissection of air into the transverse mesocolon during double-contrast barium enema. Gastrointest Radio 1990; 15: 76-7.

9 Frimann-Dahl J. Roentgen examination in acute abdominal disease. 3rd edn, 1974; pp 55-9.

10 Williams JL. Pneumatosis cystoides intestinalis involving the left half of the colon and rectum. Br $\mathcal{F}$ Surg 1961; 49: 67-9.

\title{
A seizure and odd behaviour in a 79-year-old man
}

\author{
GH Jenner
}

A 79-year-old man, widowed one week, presented to the Accident and Emergency department unconscious following a grand mal epileptic fit. His daughter described episodes of peculiar behaviour over the last six months, including one lasting 30 minutes when he woke from sleep shouting "I must save Mr Gorbachev". Laboratory results were as follows: urea: $8.0 \mathrm{~mm} / 1$ (normal <6.7 mm/1); electrolytes: sodium $141 \mathrm{~mm} / 1(135-145 \mathrm{~mm} / 1$ ), potassium $4.7 \mathrm{~mm} / 1$ (3.5-5.0 mm/1); blood sugar $<1 \mathrm{~mm} / 1$. Electrocardiogram showed left bundle branch block.

He was admitted to hospital. Two and a half hours later he became violent and abusive. A bedside finger prick blood glucose BM Stix was $<1.7 \mathrm{~mm} / 1$.

\section{Questions}

1 What is the most likely cause of his presenting symptoms?

2 What diagnoses should be considered and why?

3 What investigations would be helpful?

4 What are the options for treatment in the short and long term? 
Answers

\section{QUESTION 1}

Recurrent attacks of hypoglycaemia (box 1). In the absence of diabetes mellitus and with such a profoundly low blood glucose, an insulinoma is a strong possibility.

\section{QUESTION 2}

The causes of hypoglycaemia are listed in box 2. Hypoglycaemia is usually the result of problems with antidiabetic treatment, in particular sulphonylureas but also after many years of insulin therapy. In this situation, however, typical symptoms and signs are often absent. Adrenergic warning responses may be less after many years of diabetes mellitus. ${ }^{1}$ Some $20 \%$ of patients on sulphonylureas may experience low blood glucose. ${ }^{2}$ Hypoglycaemia is the most important and most commonly fatal adverse effect of sulphonylureas. ${ }^{3}$ Relative risks rise steeply with age.

Chlorpropamide and glibenclamide appear to cause hypoglycaemia more commonly than tolbutamide and newer agents, eg, glipizide. ${ }^{3}$ This is related to half-life and excretion route (table).

Hypoglycaemia is an important cause of hospitalisation in diabetic patients, especially the elderly. ${ }^{4}$ Dietetic error, starvation, acute illness and drug dosage mistakes contribute. ${ }^{3,5}$ A reduction in carbohydrate intake is the most common predisposing factor, eg, missing meals.

A review of biochemical laboratory assessments of blood glucose at a local hospital showed that 72 patients aged 65 or more, over a two-year period had laboratory results of less than $3 \mathrm{~mm} / 1$.

Dysopyramide, ${ }^{5}$ enalapril, ${ }^{1}$ hydralazine, oxprenolol, pentamidine, anticoagulants, propranolol, salicylates (usually in the very young), and antihistamines have all been reported as causing hypoglycaemia. Alcohol is a wellrecognised cause of hypoglycaemia ${ }^{5}$ and heavy intake enhances the effect of insulin and sulphonylureas (by reduction in hepatic gluconeogenesis). Hypoglycaemia has been reported following bladder irrigation with ethanol-containing fluid. ${ }^{6}$

\section{QUESTION 3}

The investigations which may be considered helpful in this case are shown in box 3.

Results in this patient showed a blood glucose of $<2 \mathrm{~mm} / 1$, serum insulin $57 \mathrm{pmol} / 1$ (making insulinoma likely), C peptide $743 \mathrm{pmol} / 1$ (confirming endogenous insulin secretion). No insulinoma was seen on

Table Metabolism of some antidiabetic agents

\begin{tabular}{lll}
\hline Drug & Half-life $(h)$ & Metabolism \\
\hline chlorpropamide & 35 & excreted unchanged by kidney \\
glibenclamide & 10 & liver conversion to inactive metabolite \\
tolbutamide & $4-5$ & liver conversion to inactive metabolite \\
glipizide & $2-4$ & liver conversion to inactive metabolite \\
\hline
\end{tabular}

abdominal ultrasound. The sulphonylurea screen was negative and urea and electrolytes were within the normal range. The short synacthen test gave a normal result ( 0 min cortisol $321 \mathrm{mmol} / 1,30 \mathrm{~min}$ cortisol $706 \mathrm{mmol} / \mathrm{l}$ ). The 30-minute specimen should show an increase of at least $200 \mathrm{mmol} / \mathrm{l}$ over the 0 -minute specimen and reach $500 \mathrm{mmol} / \mathrm{l}$ or more.

\section{QUESTION 4}

Treatment of an acute attack: $50 \mathrm{ml} 50 \%$ glucose intravenously, glucagon $1 \mathrm{mg}$ int-

\begin{tabular}{|l|}
\hline Hypoglycaemia: symptoms \\
\hline Adrenergic \\
- sweating \\
- visual disturbance \\
- tremitations \\
- weakness \\
Neurological \\
- confusion \\
- behavioural abnormality \\
- dits, coma \\
- loss of concentration \\
- transient neurological deficit \\
\hline
\end{tabular}

Box 1

\begin{tabular}{|l|}
\hline Hypoglycaemia: causes \\
\hline - problems with anti-diabetic treatment \\
- alcoholism \\
- drugs \\
- adurvation \\
- factitious hypoglycaemia \\
- adrenal insufficiency (Addison's disease) \\
- nonulinoma \\
non-islet cell tumours, eg, malignant \\
adrenal metastases \\
- large malignant mesenchymal tumours, eg, \\
spindle cell sarcoma, rhabdomyosarcoma, \\
- neuroblastomas (Doege-Potter Syndrome) \\
- rengestive heart failure \\
- hepatic failure \\
\hline
\end{tabular}

Box 2

\section{Hypoglycaemia: helpful investiga- tions}

- blood glucose: repeated at intervals when patient symptomatic

- urea and electrolytes and short synacthen test: help to confirm adrenal insufficiency

- serum insulin and $C$ peptide (taken at the same time as the blood glucose): these tests can detect insulinoma and differentiate it from factitious hypoglycaemia

- sulphonylurea screen

- abdominal ultrasound, CT scan, MRI scan, angiography: to locate intra-abdominal causes, especially insulinoma 
ramuscularly or subcutaneously if intravenous injection is difficult.

In the short-term, treatment can then be continued as follows: prednisolone $10-20 \mathrm{mg}$ daily, together with diazoxide, $5 \mathrm{mg} / \mathrm{kg}$ daily in divided doses, (usually $100 \mathrm{mg}$ tid). Diazoxide can cause nausea and vomiting but is useful in managing chronic hypoglycaemia from endogenous insulin secretion. It has no place in acute attacks. Guar gum may also be considered. By affecting carbohydrate absorption, it may 'even-out' peaks and troughs in blood glucose.

In the longer term, surgery is the definitive treatment. Where surgery is high risk or refused, diazoxide may be continued. The use of other drugs is discussed below.

\section{Discussion}

A common problem faced by general practitioners and hospital doctors alike is the elderly patient with hypoglycaemia. Such a patient may present atypically with confusion, behavioural changes or 'funny turns'. More serious consequences such as seizures or falls with fractures may result. The confusion and abnormal behaviour caused by hypoglycaemia may be attributed to mental deterioration in the dementing process and result in a decision that nothing can be done. That hypoglycaemia might be a cause may be ignored.

Insulinoma is a pancreatic islet cell tumour of the beta cells. Uncommon at all ages, the median age of presentation is 50 years, $10 \%$ of patients are over 70 years and $60 \%$ are female. In the elderly, insulinoma presents a difficult diagnostic problem.

Insulinomas usually occur in the pancreatic tail. More than one may be present and their small size makes detection difficult. They may secrete additional hormones, eg, gastrin, adrenocorticotropin, glucagon, and somatostatin. Symptoms may be present for months or years before diagnosis. Blood glucose tends to fall slowly and neurological symptoms predominate, eg, confusion, drowsiness, grand mal fits, abnormal behaviour. Weakness, tiredness, sweating and tremor also occur.

Patients may complain of excess hunger but do not commonly gain weight. Most demonstrate classic signs of hypoglycaemia after exercise or missing a meal. Alcohol, sulphonylureas

1 Bell DS. Hypoglycaemia induced by enalapril in a patient with insulin resistance and non insulin dependent diabetes mellitus. Diabetes Care 1992; 7: 934-6.

2 Jennings A, Wilson MR, Ward JD. Symptomatic hypoglycaemia in NIDDM. Patients treated with oral hypoglycaemic agents. Diabetes Care 1989; 3: 203-8.

3 Ferner RE, Neil HW, Sulphonylureas and hypoglycaemia. Ferner RE, Neil HW, Sul

4 Stcepka M, Rogala H, Czyzyk A. Hypoglycaemia, a major problem in the management of diabetes in the elderly. Aging (Milano) 1993; 2: 117-21.

5 Seltzer HS. Drug-induced hypoglycaemia. A review of 1418 cases. Endocrinol Metabol Clin N Am 1989; 1: 163-83.

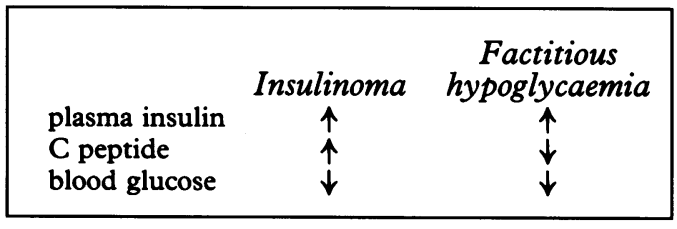

Box 4

or fasting increase the likelihood of symptoms. Misdiagnosis occurs in older patients, with symptoms attributed to age or psychological problems. 'Whipple's triad' is the diagnostic feature, namely symptoms of hypoglycaemia with low blood glucose at that time and relief of symptoms by correcting blood glucose.

Serum insulin is inappropriately normal or high when blood glucose is low. C-Peptide will also be released in proportion to the insulin released from the insulinoma. If exogenous insulin is administered, $C$ peptide levels are suppressed (eg, factitious hypoglycaemia). Factitious hypoglycaemia is unusual in the elderly. Secret takers of insulin and sulphonylureas are usually women aged 30-40 working in health-related jobs. Sulphonylurea levels can be measured in plasma.

Local excision or enucleation is the treatment of choice ${ }^{7}$ and is successful in $90 \%$ of cases after careful localisation with MRI or intraoperative ultrasound. ${ }^{10,11}$ Non-surgical treatment is usually with diazoxide, ${ }^{8,9}$ although phenytoin, glucagon, propranolol and octreotide have also been used. Malignant tumours may be treated with 5-fluorouracil or streptozotocin.

\section{Conclusion}

The causes of hypoglycaemia range from the common, usually antidiabetic drugs but also a number of other drugs not primarily used to lower blood glucose, to the unusual, such as insulinoma. Hypoglycaemia can be fatal. It is vital that it is recognised and treated.

\section{Final diagnosis}

Recurrent attacks of hypoglycaemia due to an insulinoma

Keywords: hypoglycaemia, insulinoma

6 Hahn RG. Blood sugar after ethanol. Monitoring of irrigating fluid absorption in transurethral surgery. Acta

7 Feldman JM. Carcinoid and other metabolically active tumours in the elderly. Clin Geriatr Med 1987; 3: 743-64

8 Grant CS, Van Heerden J, Charboneau JW, James EM, Reading CC. Insulinoma. The value of intraope
rasonography. Arch Surg 1988; 123: 843-8.

9 Liessi G, Pasquali C, D'Andrea AA, Scandellari C, PedraLiessi G, Pasquali C, D'Andrea AA, Scandellari C, Pedra-
zzoli S. MRI in insulinomas: preliminary findings. Eur $\mathcal{F}$ Radiol 1992; 14: 46-51. 